\title{
PERIODISMO ..
}

\section{Don Ricardo Palma, periodista...}

Hace treinta años, los pueblos del Perú se conmovian al conocer la notic:a de que en el entonces tranquilo balneario de Miraflores, se había extinguido la vida del insigne autor de las Tradiciones Peruanas. Si en verdad se marcaba el término de la existencia terrena de Don Ricarcio Palma, nacido en Iima el 7 de febrero de 1833 en una casa de la pintoresca calle del Puno, ingresiaja de lleno a la Inmorta!idad. Por los iniciales dias del mes de octubre de 1919, una huelga de gráficos impedía la regular aparición de los periódicos de la capilal y sólo circulaba una hoja trak aiada por entusiastas periodistas limeños en su afán de evitar que persistiesen las molestias projenientes de la falta de oportunas informaciones. OMe encontraba a la sezón cursando estudios de media en el Colegio fíacional de San Luis Gonzarja de lca y recuerdo que al conocer la dolorosa noticia, escribi la primera crónica suscrita con el seudónimo de Jovel y dedicada a rendir homenaje al ilustre tradicionista que constituía una de mis predilecciones literarias. - Hoy, al cabo de tres decenios por obra de esa actualidad periodística, a que acaba de aludir nuestro distinguido Director, Corpus Barga, me toca la suerte de dedicar emocionadamente esta lección del curso de Historia del Periodismo a ese genial espíritu, que inspiró mi iniciación en el oficio.

Si recorremos la ya copiosa bibliografía referente a Don Ricardo Palma, encontraremos que se cuentan nutridos estudios sobre distintos aspectos de su vida y de su obra. Se le ha estudiado como político, pero hista ahora no se ha reparado en sus actividades periodísticas, a pesar de que reiteradamente aludió a ellas, considerándose como periodista profesional. Se ha sostenido, quizás con excesiva ligereza, que Palma no fué periodista. No resulta dificil rebatir este inconsistente aserto y nos bastará tan sólo invocar sus declaraciones autobiográficas, las 
fidedignas referencies trasmitidas por su dilecta hija Angéliea y la rica documentación recolectada por Guillermo Feliú Cruz, a quien debemos uno de sus meicres derroteros para seguir las etapis vitales de Palma. Nos toca, pues, en la labor docente que generosamente se nos ha confiado en la Escuela de Periodismo de la Universidad de. San Marcos, acentuar la nota nácionalista y. colocar a Don Ricardo Palma en la gallarda posicićn que le corresponde en lạ Historia del Periodismo Peruano. Asi honramos su memoria y su proyección gloriosa enaltece a nuestro gremio periodistico.

Encontramos nítida constancia de los comienzos peridísticos de Palma, en estos párrafos de una carta que dirigió al colombiano Luis Capella Toledo y en los cuales dice:

"Recibi, mi genera! y amigo, su estimeble carta del 19 de enero \{1883\%, y con ella el precioso autógrafo de mi amigo y maestro fulio Arboledr. Era yo casi un niño cuando conocí a don Julio en la rejacción de El/ntérprele, diario de Lima, en el que era yo, a la vez que esludiaba en el Colegio y escribía mis primeros versos, ayudante del cronista".

Angélica Palma esclarece este punto así:

"En el periodismo ganó Palma el primer dinero: una onza de oro mensual que, como remuneración a su trabajo de cronistas principiantes, se embolsicaban felices él y Luciano Benjamín Cisneros, que llegaría a ser elocuentisimo orador forense y parlamentario. - No sabíamos Luciano y yo qué íbamos a hacer con lanta plata - réería Palma, recordando la alegría de ambos en tan señalada ocasión".

También nos relata lo siguiente:

"A poco separóse Ricardo Palma de la Marina; los ocho años que permaneció en ella tueron de importancia decisiva para su porvenir de escritor. La prensa de entonces guarda numerosas manifestaciones de su actividad durante ese período, principalmente El Hera!do de Lima, de honrosa memoria en nuestro periodismo por su sereno razonar y el elevado tono que caracterizaron las lides políticas y doctrinarias sostenidas por el fundador del diario, Toribio Pacheco, y por sus compañeros y sucesores, Corpancho y Mansilla". 
Case recordar e! interesante hallazgo de César Miró, quien encontró los primeros versos de Palma, aaprecidos en la edición de El Comercio, correspondiente al 31 de agosto de 1848 , lo que demuestra que los quince años pulsaba la lira.

En cuanto a la actuación peridística de Don Ricardo Palma, hay constancia expresa de que fué redactor de los siguientes periódicos: 'El Liablo", 1848; "El Burro", 1852; "El Liberal", 1858; "La Revisla de Lima": 1859-53; "Ia Campana", 1857; "El Constitucional", 1867; "La Broma", 1878-79; "La Revista Peruana", 1879; "El Ateneo", 1887; "La Revista de Sudamérica", 1861. A estas referencias consignadas en la "Bibliografía de Palma" por Sturgis E. Leavitt, habría que agregar las indicacio nes de Paz Soldán, en su Biblioteca Peruana, así como su conocida intervención en "La Zamácueca Politica", 1859, donde suscribió las famosas "Semblanzas" cor su prelerido seudónimo de Job.

No se puede deiar de apuntar que en los ejemplares de "El Burro", que se conservan en la Biblioteca Nacional, Don Ricardo Palma, escribió estas proféticas palabras: "Fué este el primer periódico que redactó en mis días de colegio. Despapuchado propio de un muchacho de 19 años. De buena gana quematía hoy estas burradas. Lima, 1885. R. P. "Del incendio de 10 de mayo de 1943, se salvó parcialmente esta reliquia de la hemeroteca peruana.

Con las inquietudes políticas de Palma y su participeción en el asalto a la casa del Presidente Castilla, en la esquina de Higuera y Divorciadas, se podria tejer una sabrosa reseña. LaSintentona revolucionatia comenzó en uñoaltar masónicoly Y Palmarłáconcluye asilándose en la Legación de Chile, a cargo de un culto diplomático, el señor Astaburuaga. Se discutió el asilo. Al fin se concedió. Entonces, se acostumbraba que el diplomático protector llevase del brazo al político asilado hasta dejarlo a bordo de un barco que lo transportase al destierro. Don Ricardo marchó a tierras del sur y portaba una elocuente misiva dirigida a una distinguida dama chilena. En ella se define su vocación periodíslica. Dice así:

"Lima, Diciembre de 1860.

Señora doña Rosario Orrego de Uribe, Valparaiso.

Estimada amiga: don Manuel Ricardo Palma, que entregará a Ud. esta carta de presentación y de especial recomendación, es un joven peruano, vecino de Lima, que por una desgraciada circunstancia política sale desterrado de su patria y establecerá su residencia en ese puerto. 
Como algunos chilenos sin experiencia de la vida política y partidarios de un concepto de libertad irrealizable, el joven Palma, con otros compañeros, entre ellos el señor Gálvez de verdadera valía, conspiraron aquí contra el Presidente General Castilla y perdieron la partida, motivo por el que va ahora desterrado. El joven Palma, a quien he tratado con alguna familiaridad, no es felizmente, un político, y me complazco en declarárselo a Ud. Ilusionado con las especulaciones teóricas de sus amigos, cometió el error de seguirlos y mezclarse en un motín que no tuvo por objeto, como lo ha dicho la prensa oficial, el proyecto de asesinar al Presidente. El es un escritor de verdadero mérito representa al grupo de jóvenes literatos de Lima y ha descollado como poeta, como escritor festivo, historiador y dramaturgo. Ha desempeñado también algunos cargos públicos de consideración; pero donde más se ha señalado ha sido en el periodismo.

Por la seriedad de su carácter tranquilo y bondadoso, como también por sus meritorias condiciones de escritor llamado a ilustrar altamente el nombre de su patria, me he permitido presentárselo a Ud. para que lo relacione y atienda en su nueva vida de desterrado. Es pobre, pero digno. Comprometería Ud. altamente mi gratitud y tâmbión en especial la del señor Palma, si lo pusiera en contacto con la gente de letras que Ud. allí preside contan singular éxito: pués de suscescritos y talentos ha de procurarse el pan en tierra extraña.

Sin otro particular se ofrece de Ud., estimada amiga, su respetuoso admirador. F. S. Astaburuaga".

El testimonio de la capacidad de Palma como periodista es definitivo. En Valpariso y en Santiago, actuó con eficiencia en el periodismo y sostuvo una original polémica por sus fervorosos principios americanistas con el español José Santos Tornero, propietario y editor de "El Mercurio" porteño, quien no aceptó insertar en las columnas del periódico artículos ofensivos para su patria.

Toquemos un interesante aspecto de la labor literaria de Don Ricardo Palma relacionado con el periodismo. En "Chico Partido" que figura al frente de la primera serie de las Tradiciones Peruanas, escribía lo siguiente:

"Sin que signifique un arranque de vanidad, creo que, ya que no se me reconozca otro mérito, nadie me disputara el de haber 
despertado en la Américd latina, el gusto do exhumar tradicicnes, y puesto a la modi lo que hoy se llama literatura tradicioralista. Lntes que yo, ni en ivíjico. Chila y las repúblicus del P.ala y Colorricia, pensj acdie en escribir tradiciones en la for-

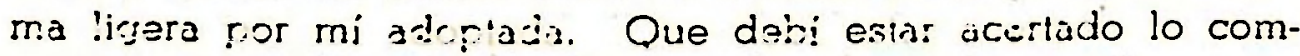
priebe al cronito nirncos de imiludores que he tenido.

I! autci, ante da compajisarlas en: libro, ajopió el sistema de publick: en los periudess tradiciones, a reedida que iban saiendo do su plumi. Ls se diba tiempo para escuchar la voz de criticos imparciales y rectificar errores en que, por ignorencia o sescuido, Dido ir.clir.r. A pesar de eso, no es noco

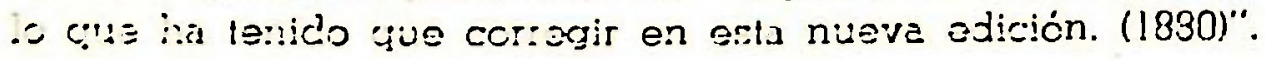

Antes quis el libro, los perićdicos fueron los vehiculos de las célebres Tradiciones Peruanas.

Liezan las amargas horis de la Guerra del Pacilico. En el incendio de Mirsfores, pierés Folma, su hogar y su biblioteca aue había formado con t.ntos sacrificios. Bien se comprende lo que significa para un homlese qua aina las letras verse privado de sus librcs, su más preciade tesc:c.

En una carta dirigida a Agrieros, dice así:

"Yo no me ousjo. Las leiras no han sido ingralas para conmigo, lo que ino deja de ser milogroso en nuestros países. No me hàn dado pan, que digamps pero han nopularizado mi nombre en los pueblos donde se hábla castellatio. Si me hubiera sido posible, yo no habría querido ser olra cosa que hombre de letras; pero, desgraciadamente, en nuestras repúblicas todos to nemos que quemarnos en esa arena ardiente que se llama poí́tica. Hasta 1075, viví en ella, ya como periodista, ya como diputado y senador, ya como secretario de uno de nuestros presidentes o ya como subsecretario en el ministerio. Cuando me creía alejido para siempre de la vida pública, y residía a inme-. diaciones de Lima, en una casita de campo, consagrado exclusivamente a las letras y a mi familia, sobrevino la guerra con Chile y el incendio de Chcrrillos y Miraflores. En éste fué presa de las llamas mi casa, perdiéndose el mobiliario y, lo que me fué más sensible, ni librería, que constaba de más de cuatro mil volúmenes, en su mayor parte obras de escritores americanos, y que había formado en largos años y a costa de no pcco dinero". 
Palma, en esos nomentos de angustia y de penuria, vuelve al periodismo. Su hija Angślica nos reláta la situación:

"Había que vivir, y para vivir se necesitaba dinero; también de la Argeritina llegaron los primeros recursos, enviados por La Frensa, de Buenos Aires, pagadora liberal de colaboraciones. Tampoco se mostró tacaño otro perićdico, Las Novedades, de Nueva York, dirigido nor el español don José García, que reunio en un tomito las tradicicnes sobre El Demonio de los Andes, publicadas en su semanario. Colaboraciones exclusivamente literarias, reportaron a su autor honra y provecho y estuvieron libres del peligroso aspecto de los que, sobre temas de la dramática aciualidad, mandaba a La Estrella de Panamá, firmadas con seudónimo que las conocidas peculiaridades del estilo de Palma hicieron fácilmente descifrables".

Al término de la lucha, recibe la generosa oferta del ilustre fundador de "La Prensa" de Buenos Aires para ocupar una plaza de redactor. José C. Paz, da con ella nueva muestra del sentido de noble solidaridad periodística internacional que le anima, ya que también con otro gran periodista peruano, el Doctor Cesáreo Chacaitana, el adimirable director de El Nacional, había tenido el mismo gesto cordial, incorporándolo a la redacción de su diario, cuando se vió falto de recursos en Buenos Aires. Bien sabemos que Palma desiste de su proyeztado viaje a la capital argentina para entregarse a la grandiosa obra de reconstruir la Bibliotecar Nacionale fundada porvel General San Martín.

Otra actividad periodística de Don Ricardo Palma, la tenemos en el envío de correspondencias a El Comercio, cuando viaja a España para participar como delegado del Perú en las fiestas conmemorativas del Cuarto Centenaiio del Descubrimiento de América. En la obra dedicada por el erudito Decano de la Facultad de Letras y Filosofía, Doctor Aurelio Miró Quesada Sosa, a la biografía de su abuelo, el esclarecido periodista Don José Antonio Miró Quesada, ofrece cautivante detalles al respecto.

Hemos señalado, meramente algunos rásgos de la labor periojistica de Don Ricardo Palma. Toca a los alumnos del curso de Historia del Periodismo investigar sobre sus aportes. Algunos de ellos permanecerán envueltos en el misterio del anonimato, pero éstos podrán determinarse, porque Don Ricardo poseía un estilo inconíundible. Revisando un libro de recortes de periódicos antiguos, encontramos cierta ano- 


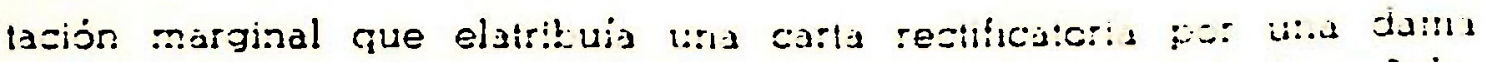

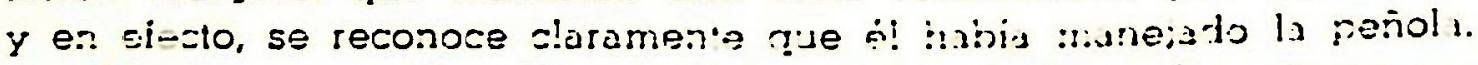
f.itirnemos que Don Ricarto Falma lue veriozisis. Lu prime:a cnza gue garó en su vidu. so la preporcionj e! ofici. Fue esa moneda de aúres metal de buena $k \%$ el a.jurio de sus doradas TRADICiONES PERLA:iA.S. magnificas joyas de is literatura unire:sat.

losè M. Véiez Plcassso.

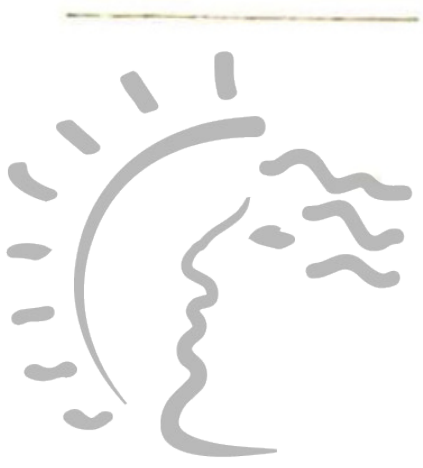

Biblioteca de Letras "Jorge Puccinelli Converso» 